\title{
Skill Transfer between Organizational Workgroups: The Interpersonal Dimension
}

\author{
Ruediger OEHLMANN *
}

\begin{abstract}
The paper describes two related studies that investigated skill transfer between the same workgroups of a bank over a period of 3 months. During this period the smaller group trained the larger group in customer relationship management skills. At the beginning and the end of this period, group members had to describe their interpersonal and intergroup relationships in diagrams using predefined diagrammatic items. The analysis of the diagrams showed that interpersonal characteristics such as friendship, respect, good manners, and interpersonal contact correlate higher with skill transfer (significance level $\mathrm{p}<0.01$ ) than intergroup characteristics, which had no significant correlation with skill transfer. A comparison of the two sets of diagrams after two weeks and three months also showed a polarization effect, in that after three months most relationships became more harmonious or more conflict-laden. The latter relationships led to a reduction in skill transfer. This result modifies the contact hypothesis, which emphasized the benefits of close intergroup contact. Consequences for intergroup skill transfer are discussed.
\end{abstract}

Keywords : Skill Transfer, Workgroups, Social Diagrammatic Language, Intergroup Relationships, Interpersonal Relationships.

\section{INTRODUCTION}

Traditionally, skill acquisition has been investigated in cognitive psychology. For instance Gobet and Simon (1996) suggested that expert chess players have stored knowledge in the form of schematic structures, referred to as templates. In his ACT theory, Anderson (1993) assumes that skill acquisition involves knowledge compilation - a shift from the use of declarative knowledge to the use of procedural knowledge as a result of prolonged practice. A related stance was taken by Ericsson (1996), who argued that deliberate practice is necessary and sufficient for expertise to develop. Often this type of work considers skills only in a cognitive-motoric sense. This might be too limited a perspective for more complex domains such as skills required in customer relationship management.

Moreover, if the acquisition does not just involve interactions between a task scenario and the learner, but a trainer as well, then skill acquisition becomes

* Kingston University London, Faculty of Computing, Information Systems and Mathematics skill transfer and includes a social component. If the skill transfer takes place in an organizational setting, often one or more workgroups are involved as well.

Such intergroup settings have been addressed in the social identity theory (SIT) (Tajfel, 1978 ; Tajfel and Turner, 1979). Brewer and Gaertner (2004) have described two premises the theory is based on :

1. Individuals map continuous variables on discreet categories and minimize perceived intra-category differences and emphasize inter-category differences. These categorical distinctions enable individuals to understand their social world.

2. One important categorical distinction is the ingroup-outgroup distinction, which has affective and emotional significance.

Based on these premises, the theory proposes an intergroup schema with the following characteristics :

1. Intergroup accentuation principle : Identification with category characteristics and contrast to other categories, so that members of the ingroup are considered as closed in characteristics (ingroup cohesion) that the members of an outgroup. 2. Ingroup favoritism principle: Positive affects 
such as trust are applied to members of the ingroup but not to members of the outgroup.

3 . Social competition principle: Ingroup and outgroup are socially compared with negative interdependence.

If in an organizational skill transfer, the trainer is a member of one workgroup and the learner a member of another workgroup, SIT suggests that this situation would lead to increased competition and distrust between trainer and learner. In fact the learner may turn to members of his own group for help, rather than utilizing the higher competence of the trainer.

The contact hypothesis $(\mathrm{CH})$ was initially introduced as a set of strategies to reduce intergroup prejudices and discrimination in interracial relations in the United States (Allport, 1954 ; Watson 1947). The basic idea was that if separation and unfamiliarity leads to prejudices, then the effects could be reversed by increasing contact between members of different groups. Already Allport (1954) had proposed strategies such as social and institutional support, acquiring new accurate information about the other group, achieving equal status between groups, and cooperative interaction between members of both groups. These strategies are a necessary condition to make intergroup contact successful.

In laboratory experiments a number of other moderating factors have been identified, such as frequency and duration of intergroup interactions (Worchel, et al., 1977 ; Wilder and Thompson, 1980), the presence of intergroup anxiety (Stephan and Stephan, 1984 ; Wilder and Shapiro, 1989), the structure of cooperative tasks (Bettencourt, Brewer, Croak, and Miller, 1992 ; Deschamps \& Brown, 1983 ; Gaertner, Dovidio, Rust et al., 1999 ; Marcus-Newhall, Miller, Holtz and Brewer, 1993), and the outcome of cooperation (Worchel et al., 1977).

If applied correctly to an intergroup skill transfer, the contact hypothesis could balance the negative predictions of SIT. However this assumption needs to be qualified in the light of a recent model on group development. In a study of the development of workgroups, Oehlmann (2007) has identified four stages:

1. Individual Identity $:$ In this stage, the individual focuses on his or her specific physical and personality characteristics.

2. Individual-Supported Identity : Now individual relationships within the group are formed with the objective to find support for task the individual has to perform.

3. Group-Supported Identity: Now the individual aims at supporting other group members.

4. Group Identity: Here the focus is on the ingroup's boundaries and status within the wider domain of groups.

The first three stages are based on individual characteristics or relationships. This raises the question, whether skill transfer depends mainly on group contact, as the contact hypothesis suggests, or on individual contact as the group development model suggests.

This question has been addressed with two related studies in a European bank. In order to protect the commercial confidentiality, throughout this paper the code name X-Bank will be used instead of the actual name. Also for the departments and participants in this study, code names will be used. X-Bank had three departments that received customer complaints as part of the normal banking operations. These were the general counter department that conducts the counter operations, the trading department for bonds, shares and investment funds, that was responsible for buying and selling to private investors, and the business department that supported client businesses and focused on the acquisition of new clients. Customer complaints were received by any of these departments and then passed on to the customer complaints department that dealt with them. However, the bank management realized that the customer complaints department became overloaded with minor complaints, which had no legal or business ramifications, but rather where a customer relationship issue. It was therefore decided that this type of complaints should be handled by the department that received it. For a transition period, the departments would receive training in customer relationship management from the customer complaints department. During this phase the members of the departments had to describe their relationships with the customer complaints department and also their individual relationships with members of that department in the form of relationship diagrams that are described in the next section.

It was predicted that

1. skill transfer correlates positively with character- 
istics of personal relationships between trainer and learner, such as respect and trust, and

2 . with increased contact skill transfer will improve.

The remainder of this paper will first describe the method of social relationship diagrams, followed by a description of the two studies. The last section will discuss the results in relationship to SIT, the contact hypothesis, and the group development model.

\section{SOCIAL DIAGRAMMATIC LANGUAGE (SDL)}

We will now provide a brief summary of the Social Diagrammatic Language (SDL). The details, in particular the graphical elements, can be found in (Oehlmann, 2006). The language consists of a set of elements for describing the social context.

The elements include agents, attributes and actions associated with a given agent and relations between agents. In addition, the language facilitates the description of emotions and conflict resolution styles adopted by the group members. The emotion scale is based on a set of opposite pairs proposed by Ortony et al. (1988) : Happy-for vs. Resentment, Gloating vs. Pity, Joy vs. Distress, Pride vs. Shame, Admiration vs. Reproach, Love vs. Hate, Hope vs. Fear, Gratification vs. Remorse, and Gratitude vs. Anger. The position on a given range is indicated by a Likert-type scale from 1 to 5 . For instance a 2 combined with the Joy/ Distress pair indicated a fairly joyful feeling.

Conflict resolution styles (Baki and Hartwick 2001, Friedman et al. 2000) include : confrontational style, compromising style, obliging style, dominating style, avoiding style, problem solving style,

Elements that describe a particular view of the task domain include objects, attributes and actions associated with an object as well as relations between objects.

The current study enhances the SDL version described in (Oehlmann, 2006), in that it includes graphical elements for inter-group relations and interpersonal relations. Examples of inter-group relations are Group Competitiveness, Group Cooperation, Group Trust Group Status, Group Contact, and Group Similarity. Given two groups A and B, these elements can be used by a member of group A to express his or her view about the relationships between the two groups as a whole.

The elements that are used to describe interpersonal relationships can be grouped into three categories : elements that characterize a person, elements that describe either relationships of person $\mathrm{A}$ to person $\mathrm{B}$ or relationships of person $\mathrm{B}$ to person $\mathrm{A}$, and mutual relationships between $\mathrm{A}$ and $\mathrm{B}$. Examples for elements of the first category include competence and self-interest. The latter element indicates as how selfish or altruistic a person is considered to be. Elements of the second category are trust, respect, good manners, honoring commitment, keeping promises, and sending mixed messages. Elements of the third category are enemy/friend and similarity.

In addition, there are elements for interpersonal skill transfer and intergroup skill transfer. In contrast to interpersonal skill transfer, the intergroup skill transfer element indicates how well an outgroup as a whole supports the skill acquisition task. The example in Figure 1 shows that the elements have similar structure consisting of a label and a Likert scale. Some elements also offer a comment field.

Figure 1 indicates that the author of the graphic, $\mathrm{P} 1$, is in a slightly friendly relationship with $\mathrm{P} 4$ and also trusts him or her a bit. In addition, P1 feel slightly joyful about their relationship. In the studies reported here, it was a convention that the person at the lefthand side belongs to a different group then the person at the right-hand side.

In the following two sections, we will describe the studies, in which these elements have been used. 


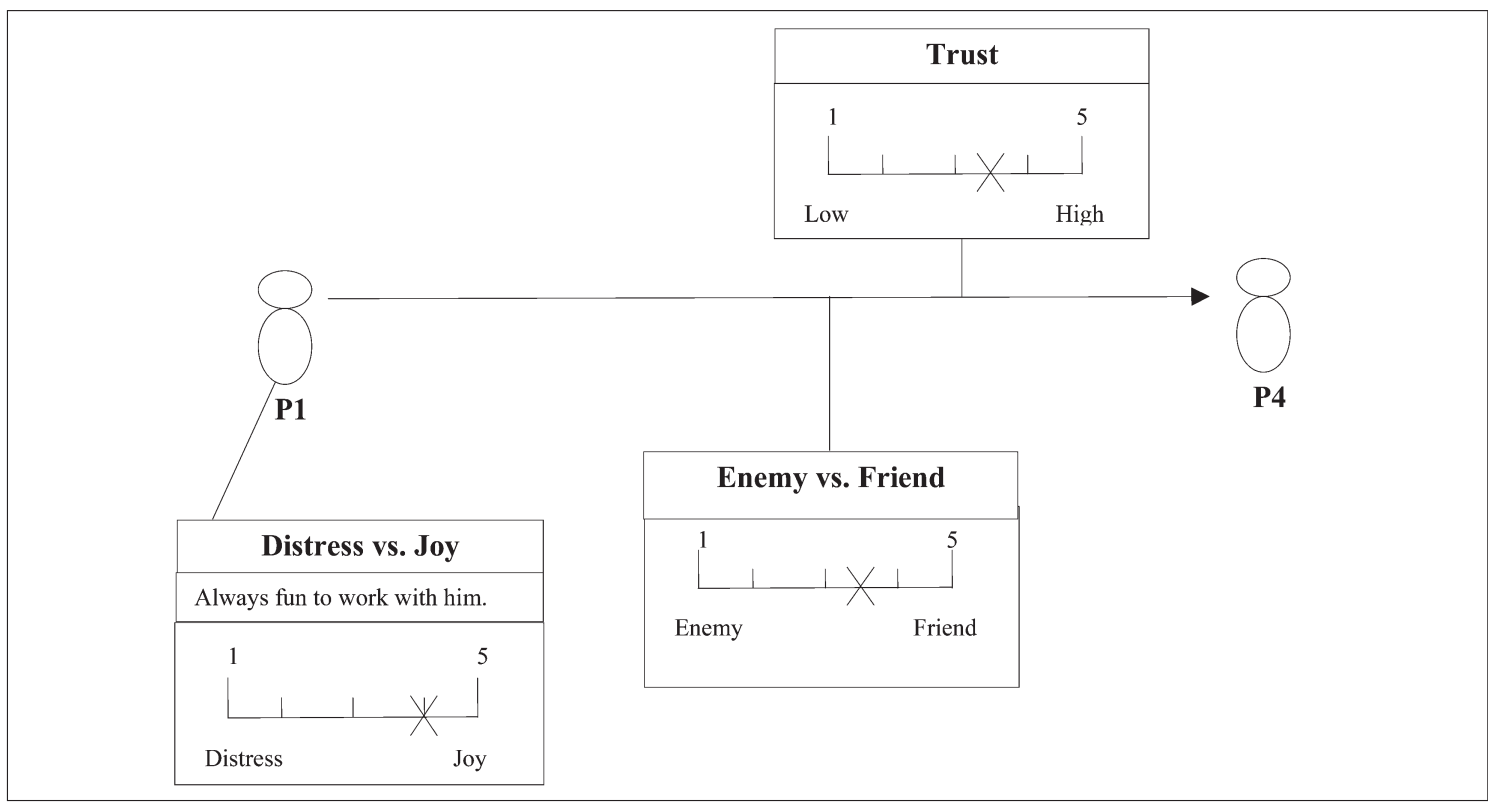

Fig.1 Example of an Interpersonal SDL Diagram

\section{3 . STUDY 1}

The first study investigated the prediction that interpersonal relationships correlate higher with skill transfer than inter-group relationships.

\subsection{Method}

\subsubsection{Design}

All participants formed two groups. The first group (learner group) had to acquire customer relationship management skills from the second group (trainer group).

\subsubsection{Participants}

Participants were 40 employees of X-Bank. 10 employees of the business department, 14 employees of the general counter department and 8 employees of the bonds and shares department formed the group of learners. 8 employees of the customer complaints department formed the group of trainers. The age range of the group of learners was 24-62 years (means 39.4 years). The age range of the group of trainers was 32 to 55 years (means 40.6 years).

\subsubsection{Materials}

Each participant received written instructions about the purpose and the procedure of the study and an instruction booklet that explained the concept of SDL

\subsubsection{Procedure}

At the beginning of the 3 month training phase on customer relationship management (CRM), each member of the learner group received a 90 minutes training on creating SDL diagrams. After two weeks of CRM training conducted by the training group, the learner group was asked to create SDL diagrams about their relationships to each of the trainers. As there were 32 participants and 8 trainers, 256 diagrams were created. They also had to create diagrams that describe their view of the relationship between the two groups.

\subsection{Results}

There were significant correlations between interpersonal skill transfer (IST) and friendship, respect, and good manners. The correlations were between IST and friendship $\left(\mathrm{r}_{\mathrm{P}}=.780, \mathrm{~N}=256, \mathrm{p}<.01\right.$, two-tailed $)$, Figure 2), between IST and respect $\left(r_{\mathrm{P}}=.737, \mathrm{~N}=\right.$ $256, \mathrm{p}<.01$, two-tailed), Figure 3 , and between IST and good manners $\left(r_{P}=.678, N=256, p<.01\right.$, twotailed), Figure 4 . Also the correlation between IST and interpersonal contact $\left(\mathrm{r}_{\mathrm{P}}=.725, \mathrm{~N}=256, \mathrm{p}<.01\right.$, twotailed), Figure 5, was high.

These were the highest correlated characteristics. 
For instance, the correlation between IST and interpersonal trust was lower $\left(\mathrm{r}_{\mathrm{P}}=.551, \mathrm{~N}=256, \mathrm{p}<.01\right.$, two-tailed), Figure 6, but still significant.

For the correlations between group-based skill transfer (GST) and group competitiveness, group status, and group contact there was no significance. The correlations were between GST and group competitiveness $\left(r_{\mathrm{P}}=-.235, \mathrm{~N}=32, \mathrm{p}=.196\right.$, two-tailed), between GST and group status $\left(\mathrm{r}_{\mathrm{P}}=-.188, \mathrm{~N}=32, \mathrm{p}=\right.$ .303 , two-tailed), between GST and group contact (rP $=.303, \mathrm{~N}=32, \mathrm{p}=.092$, two-tailed)

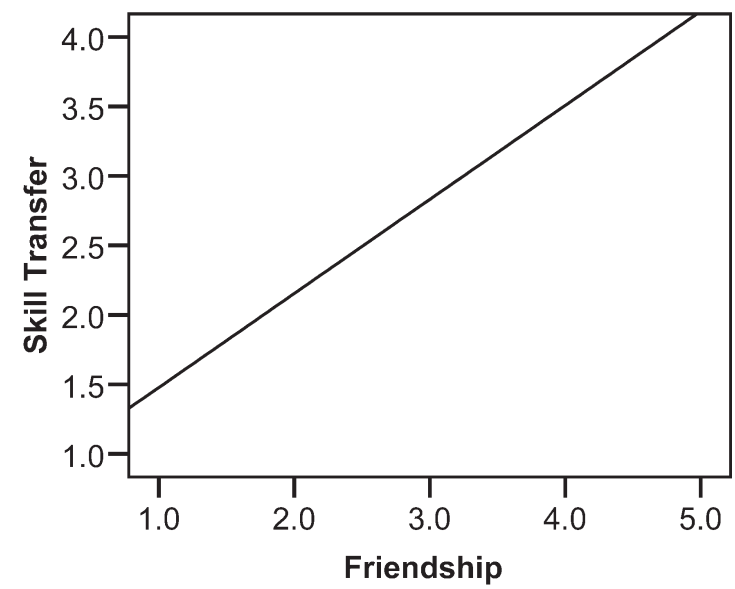

Fig.2 Skill Transfer-Friendship Correlation

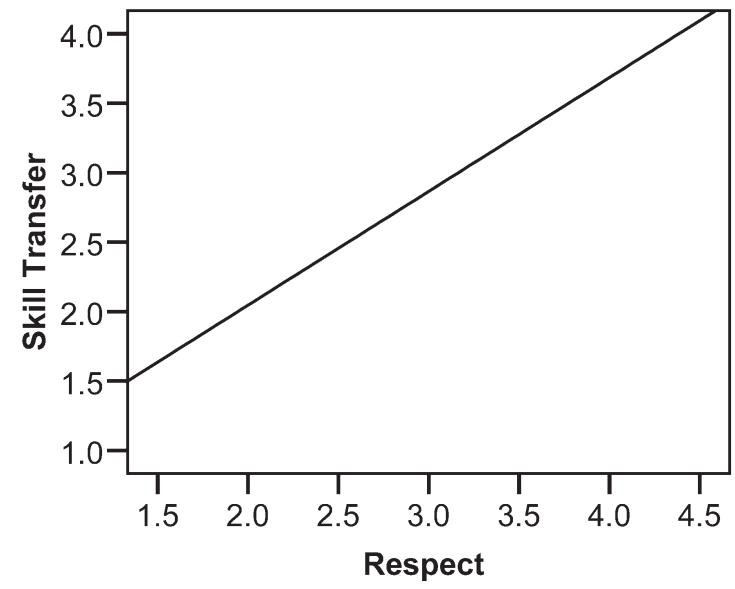

Fig.3 Skill Transfer-Respect Correlation

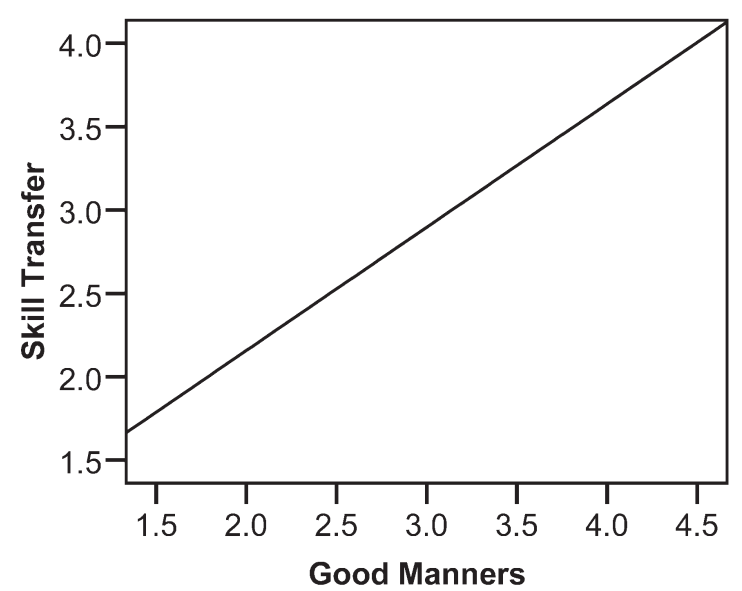

Fig.4 Skill Transfer-Good Manners Correlation

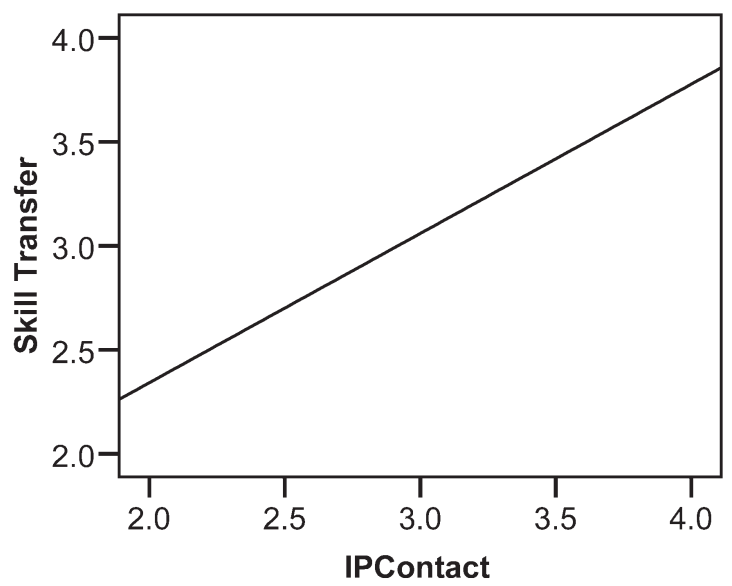

Fig.5 Skill Transfer- Interpersonal Contact Correlation

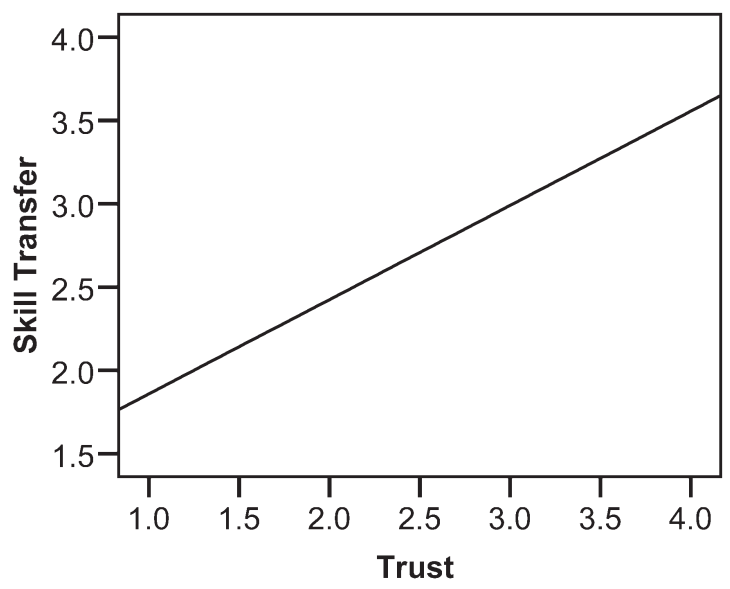

Fig.6 Skill Transfer- Interpersonal Trust Correlation 


\subsection{Discussion}

The result confirms the prediction that skill transfer correlates positively with characteristics of interpersonal relationships between trainer and learner. It did not correlate significantly with any of the intergroup characteristics that were considered. These results are consistent with the model of group development described in the introduction (Oehlmann, 2007). Most of the stages of that model involve interpersonal relations as opposed to intergroup relations. The latter type of relations is mainly used to strengthen the intra-group coherence.

However, the results modify social identity theory and the contact hypothesis with respect to intergroup skill transfer. Social identity theory suggests that positive affects apply to the ingroup but not to the outgroup. This lack of positive affects toward the outgroup should interfere with a successful skill transfer from outgroup to ingroup. However this is not the case.

According to the contact hypothesis, the increased contact between both groups during the training sessions should affect the skill transfer. Again this is not the case. In contrast, the interpersonal contact correlated significantly with the skill transfer.

Comments of the participants suggested that they consider interpersonal contact outside of office hours as particularly important for their relationships. Although the raw data of Study 1, allowed already to identify subgroups of participants who maintained private relationships, this aspect was further investigated in a second study.

\section{STUDY 2}

Given that the characteristics of interpersonal relationships correlated better with judgments on skill transfer than the characteristics of intergroup relationships, the second study investigated the prediction that there is a relationship between changes in the interpersonal relationships over time and improvement in the acquired skills.

\subsection{Method}

\subsubsection{Design}

The same participants from Study 1 had to generate a second set of SDL graphics after 3 months of training. In addition to their individual assessment of the skill transfer, it was also assessed by a questionnaire given to 350 customers who had regular contact with the participants.

\subsubsection{Participants}

Participants were the same as in Study 1.

\subsubsection{Materials}

The materials were the same as in Study 1 . In addition, a questionnaire was administered to 350 customers. The questions referred to the improvement in the customer relationship skills of the individual members of staff.

\subsubsection{Procedure}

After a training phase in the area of customer relationship management, all participants were asked to create a second batch of SDL diagrams characterizing the relationships with the members of the trainer group.

In addition the questionnaire was administered to 350 customers. 50 customers answered questionnaires about the improvement in performance of a group of 5 employees. For each of the five employees a separate questionnaire was submitted. Therefore the questionnaire data for each participant are based on 50 respondents.

\subsection{Results}

The summary data in Table 1 show a clear polarization effect.

After two weeks, the largest number of participants selected scores in the range from 2.5 to 3.5 , but after 3 months most of these participants had moved either into the range from 1-2 or from 4-5, whereas only a small number of participants could be found in the middle range between 2.5 and 3.5.

Only the trust variable follows a slightly different pattern. Again, the middle level of the scores is considerably reduced and the higher level is increased after 3 months. However, the lower level is only slightly increased.

There were a significant correlation between the means of all the scores for interpersonal skill transfer, provided by one participant and indicating how much the participant has learned, and the mean scores given by the customers for that participant $\left(\mathrm{r}_{\mathrm{P}}=.518\right.$, 
$\mathrm{N}=32, \mathrm{p}<.01$, two-tailed) .

There were significant correlations between interpersonal skill transfer (IST) and friendship, respect, and good manners. The correlations were between IST and friendship $\left(\mathrm{r}_{\mathrm{P}}=.727, \mathrm{~N}=256, \mathrm{p}<.01\right.$, two-tailed $)$, between IST and respect $\left(r_{P}=.676, N=256, p<.01\right.$, two-tailed) and between IST and good manners $\left(\mathrm{r}_{\mathrm{P}}=\right.$ $.602, \mathrm{~N}=256, \mathrm{p}<.01$, two-tailed).

The means and standard deviations of the ratings after 2 weeks and 3 months are shown in Table 2.

Table 1 Frequencies after 2 weeks and after 3 months

\begin{tabular}{|l|r|r|r|}
\hline Variable & $\begin{array}{l}\text { Scores } \\
\text { 1-2 }\end{array}$ & $\begin{array}{l}\text { Scores } \\
\mathbf{2 . 5}-\mathbf{3 . 5}\end{array}$ & $\begin{array}{l}\text { Scores } \\
\mathbf{4} \text {-5 }\end{array}$ \\
\hline $\begin{array}{l}\text { Skill Transfer } \\
\text { after 2 wks }\end{array}$ & 53 & 198 & 5 \\
\hline $\begin{array}{l}\text { Skill Transfer } \\
\text { after 3 months }\end{array}$ & 97 & 61 & 98 \\
\hline $\begin{array}{l}\text { Friendship } \\
\text { after 2 wks }\end{array}$ & 30 & 206 & 20 \\
\hline $\begin{array}{l}\text { Friendship } \\
\text { after 3 months }\end{array}$ & 109 & 28 & 119 \\
\hline $\begin{array}{l}\text { Respect } \\
\text { after 2 wks }\end{array}$ & 38 & 202 & 16 \\
\hline $\begin{array}{l}\text { Respect } \\
\text { after 3 months }\end{array}$ & 111 & 22 & 123 \\
\hline $\begin{array}{l}\text { Manners } \\
\text { after 2 wks }\end{array}$ & 41 & 201 & 14 \\
\hline $\begin{array}{l}\text { Manners } \\
\text { after 3 months }\end{array}$ & 131 & 20 & 105 \\
\hline $\begin{array}{l}\text { Interpersonal } \\
\text { Trust } \\
\text { after 2 wks }\end{array}$ & 127 & 121 & 8 \\
\hline $\begin{array}{l}\text { Interpersonal } \\
\text { Trust } \\
\text { after 3 months }\end{array}$ & 146 & 37 & 73 \\
\hline
\end{tabular}

Table 2 Means and Standard Deviation after 2 weeks and after 3 months

\begin{tabular}{|l|c|c|c|c|}
\hline Variable & $\begin{array}{l}\text { Means - } \\
\text { 2 weeks }\end{array}$ & SD & $\begin{array}{l}\text { Means - } \\
\text { 3 months }\end{array}$ & SD \\
\hline Friendship & 2.92 & 0.65 & 3.03 & 1.06 \\
\hline Respect & 2.90 & 0.59 & 3.02 & 1.03 \\
\hline $\begin{array}{l}\text { Good } \\
\text { Manners }\end{array}$ & 2.83 & 0.57 & 2.88 & 0.99 \\
\hline $\begin{array}{l}\text { Skill } \\
\text { Transfer }\end{array}$ & 2.80 & 0.57 & 2.94 & 0.97 \\
\hline Trust & 2.52 & 0.58 & 2.70 & 0.89 \\
\hline
\end{tabular}

\subsection{Discussion}

Study 2 has confirmed to some extent the prediction that with increased contact, skill transfer will improve. However, in the same period skill transfer also was worsened for some participants. In fact, there was a polarization effect that reduced the increase in the mean scores for skill transfer as well as for the interpersonal relationship characteristics, such as respect, friendship, good manners and interpersonal contact. This polarization effect is also reflected in the increased standard deviation after three months (Table 2 ). Also the relatively small increase in skill transfer $(5 \%)$ and in the other variables (between $2 \%$ and 7 $\%)$ can in part be attributed to the polarization effect.

This means that in contrast to the contact hypothesis, a prolonged contact may sometimes also have a negative effect. The discriminating factor may be the recency of experiences. If a recent positive experience reinforces a previous positive experience with the same trainer, the assessment of the relationship is also positive. Equally a recent negative experience that reinforces a previous negative experience leads to a negative assessment of the relationship. In the case of assessments in the middle range in Study 1, and subsequent negative experiences, the result established a lower assessment in Study 2. If a previous ambivalent assessment is followed by a positive experience in the contact phase the result is a higher assessment. Both changes constitute the polarization effect.

The only variable that does not completely follow this pattern is the trust variable. Generally, after two weeks the trust scores were lower than the other scores. Consequently, the number of scores in the lower range was higher. Therefore after three months, the number of scores in the lower range could not increase so much. Nevertheless also this variable showed a polarization effect in the middle and higher ranges.

The correlations between IST and the highly correlated interpersonal characteristics of Study 1 were slightly weaker than in Study 1, but still on the same significance level. The weakening of these correlations may be a consequence of the polarization effect, as participants changed their attitudes toward the trainers. 


\section{5 . Conclusion}

Study 1 has shown that some characteristics of interpersonal relationships correlate higher with skill transfer between groups, than characteristics of inter-group relationships do. It is important to note that the best results were achieved with characteristics that induce harmony into the relationship, such as showing respect, showing good manners, and maintaining friendships.

Study 2 has shown that these positive effects are only maintained, if the positive relationship characteristics are maintained; otherwise the effect may turn into the opposite. Skill transfer is worsened rather than improved. It appears that in particular the middle range of scores is vulnerable toward change in their relationships.

The possibility of a change to the worse raises the question of how such a change can be avoided or turned into a change to the better. First of all, trainers should avoid conflicts and other situations that are associated with negative affects. The data in both studies emphasize strategies to improve harmony and avoid conflict. Here common experiences outside of office hours appear to be particularly beneficial. There was only a small statistically not significant number of participants in both groups, who had developed friendships across group borders before Study 1 started. However these participants outperformed all other participants in the skill transfer dimension.

The results emphasized attitudes towards respect and accepted behavior, which usually are associated with East-Asian cultures. It is therefore to question whether these attitudes are more global than usually assumed.

It also should be noted that all participants were Caucasian Europeans of the same nationality. Although there was a difference in business culture in different groups, such as service culture vs. acquisition of new customers, ethnic cultural differences did not play a role in the design of these studies. For instance, if the training takes place between two groups of different ethnic origin, ingroup cohesion may reinforce the different social identities. In such a scenario it may be more difficult to develop positive attitudes towards members of the other group. Obviously this would require further studies. However, if such a situ- ation occurs, it appears to be even more of importance to develop harmony increasing strategies.

\section{References}

[1] Allport, G. The nature of prejudice. Cambridge, MA. Addison-Wesley, 1954

[2] Anderson, J. Rules of the mind. Hillsdale, NJ : Harvard University Press, 1993.

[ 3 ] Baki, H., Hartwick, J. Interpersonal Conflict and its Management in Information System Development. MIS Quarterly 25 (2), (2001) pp. 195-225.

[ 4 ] Bettencourt, B., Brewer, M., Croak, M. and Miller, N. Cooperation and reduction of intergroup bias: The role of reward structure and social orientation, Journal of Experimental Social Psychology, 28, (1992) 301-319.

[5] Brewer, M. and Gaertner, S. Toward reduction of prejudice : Intergroup contact and social categorization. In M. Brewer and M. Hewstone (eds.), Self and Social Identity, Chapter 13, Oxford, Blackwell Publ., 2004.

[6] Deschamps, J.-C., and Brown, R. Superordinate goals and intergroup conflict, British Journal of Social Psychology, 22, (1983) 189-195.

[ 7 ] Ericsson, K. The road to excellence, Mahwah, NJ : Lawrence Erlbaum Associates, 1996.

[ 8 ] Friedman, R., Tidd, S., Curall, S., Tsai, J. What goes around comes around: the impact of personal conflict style on work. International Journal of Conflict Management 11 (1), (2000), 32-55.

[ 9 ] Gaertner, S., Dovidio, J., Rust, M., Nier, J., Banker, B., Ward, C., Mottola, G, and Houlette, M. Reducing intergroup bias: Elements of intergroup cooperation. Journal of Personality and Social Psychology, 76. (1999), 388-402.

[10] Gobet, F. and Simon H. The roles of recognition processes and look-ahead search in time-constrained expert problem solving. Psychological Science, 7, (1996), $52-55$.

[11] Haslam, S. Psychology in Organizations. The Social Identity Approach. London: Sage Publications, 2004

[12] Marcus-Newhall, A., Miller, N. Holtz, R., Brewer, M. Crosscutting category membership with role assignment: A means of reducing intergroup bias. British Journal of Social Psychology, 32, (1993), 125-146.

[13] Oehlmann, R. The function of harmony and trust in collaborative chance discovery. New Mathematics and Natural Computation (Journal), 2 (1), (2006), 115.

[14] Oehlmann, R. The changing self during group development : Interactions between individual identity and group identity. In A. Nijholt, O. Stock, and T. Nishida (eds.) Proceedings of the $6^{\text {th }}$ International Workshop on Social Intelligence Design, Trento, pp. 245-253, 2007

[15] Ortony, A., Clore, G., and Collins, A. The Cognitive Structure of Emotions. Cambridge, UK : Cambridge 
University Press, 1998.

[16] Stephan, W. and Stephan, C. The role of ignorance in integroup relations. In N. Miller and M. Brewer (eds.), Groups in contact: The psychology of desegregation, New York : Academic Press, 1984.

[17] Tajfel, H. (Ed.), Differentiation between social groups: Studies in the social psychology of intergroup relations. London : Academic Press, 1978.

[18] Tajfel, H. and Turner, J. An integrative theory of intergroup-conflict. In W. G. Austin and S. Worchel (Eds.), The social psychology of intergroup relations. Monterey, CA : Brooks/Cole, 1979.

[19] Turner, J. Reynolds, K. The social identity perspective in inter-group relations : Theories, themes and controversies. In M. Brewer and M. Hewstone (eds.), Self and Social Identity, Chapter 11, Oxford, Blackwell Publ., 2004.

[20] Wilder, D. and Shapiro, P. Role of competition-induced anxiety in limiting the beneficial impact of positive behavior by an out-group member. Journal of Personality and Social Psychology, 56, (1998) 6069.

[21] Wilder, D. and Thompson, J. Intergroup contact with independent manipulation of in-group and out-group interaction. Journal of Personality and Social Psychology, 38, (1980), 589-603.

[22] Worchel, S., Andreoli, V. and Folger, R. Intergroup cooperation and intergroup attraction. The effect of previous interaction and outcome of combined effort. Journal of Experimental Social Psychology, 13, (1977), 131-140.

[23] Watson, G. Action for unity. New York : Harper, 1947.

（2007年12月15日 受付）

(2008年 5 月 6 日 採録)

[Contact Address]

Dr. Ruediger OEHLMANN

Kingston University London

Faculty of Computing, Information System and Mathematics, Kingston upon Thames

KT1 2EE, UK

TEL : +44-20-8547-2000

FAX : +44-20-8547-7887

E-mail : R.Oehlmann@kingston.ac.uk has obtained a B.Sc. in Psychology, a Diploma in Mathematics and Computer Science, and a Ph.D. in Cognitive Science. He is the author of some 60 peer-reviewed research papers, mainly in the area of the psychology of organizational group work. But he has also conducted investigations in cross-cultural psychology. This work mainly compared British culture with the cultures of Japan, China, and Korea. Dr. Oehlmann also has contributed to these areas by organizing a number of workshops at international conferences, mostly in cooperation with colleagues from various Japanese Universities. 